\title{
1. An Asian poverty line? Issues and options
}

\section{Stephan Klasen ${ }^{1}$}

\section{INTRODUCTION}

Using the widely used international income poverty line $(\$ 1.25$ per person per day), poverty in Asia has fallen dramatically in recent decades. In fact, the very rapid progress on absolute income poverty reduction in Asia is largely responsible that the first Millennium Development Goal (MDG) aiming to halve the incidence of absolute poverty between 1990 and 2015 has been reached four years ahead of schedule. This was achieved by particularly rapid progress in many populous Asian economies (particularly, the People's Republic of China, Indonesia, and Viet Nam), overcompensating for much slower progress in poverty reduction in sub-Saharan Africa (Chen and Ravallion 2013).

Despite this progress, it is too early to declare victory on the poverty front in Asia for various reasons. First, progress in poverty reduction remains fragile in many Asian countries and the vulnerability to poverty remains high (Klasen and Waibel 2013, 2014). Second, there is the recognition that poverty captures more than a lack of incomes, an issue covered by the literature on multidimensional poverty (for example, Rippin 2013; Alkire and Santos 2014). Progress in reducing multidimensional poverty in Asia has generally been more uneven (although there are substantial uncertainties about the data, particularly comparable data over time). Finally, in many Asian countries national poverty lines are substantially higher than the international \$1.25-a-day poverty line; in some, including the People's Republic of China (PRC) and India, they have been revised upwards to also reflect the rising aspirations of the populations in these societies. At these higher (and increasing) poverty lines, poverty is far from defeated.

Partly as a result of these factors, the Asian Development Bank (ADB) is considering whether there is merit in developing an Asia-specific poverty line. In addition, it is considering ways to derive such an Asian poverty line, closely related to the methods developed and applied by the World Bank (Ravallion et al. 2009) in deriving the international \$1.25-a-day 
poverty line but specific for the Asian situation. This chapter first discusses whether there is merit in developing an Asia-specific poverty line. We then discuss various options of developing such a poverty line, considering income and multidimensional versions of such a poverty line. We argue that there can be some merit in developing an Asian poverty line and that, in the case of income poverty, it would be best to ground such an Asian-specific poverty line in a consistent method of generating national poverty lines using national currencies rather than generating a purchasing power parity (PPP) adjusted poverty line in international dollars (see also Klasen 2013a; Klasen et al. 2015). It is important that such a poverty line also considers relative poverty in its assessment to reflect the rising aspirations of Asian societies (see Ravallion and Chen 2011; Chen and Ravallion 2013). In terms of multidimensional poverty lines, there is merit in developing an Asia-specific multidimensional poverty index (MPI) that takes into account the specific living conditions of Asian societies.

\section{ADVANTAGES AND DISADVANTAGES OF AN 'ASIAN' POVERTY LINE}

Before discussing options to derive a poverty line for Asia, it is important to first discuss whether it is useful to develop such a line to begin with. We consider four possible arguments for an Asia-specific poverty line. First, it could be argued that conditions in Asia are so different from other parts of the world that it justifies a different poverty line, in the sense that it would reflect these particular circumstances. For example, households tend to be smaller than in Africa, family ties are quite strong, and the provision of public services by the state is substantial. To the extent that this is the case, it might justify a lower poverty line, measured in terms of private per capita incomes because fewer private incomes are required to achieve a certain level of well-being. However, it is not obvious that these apparent differences justify a peculiar Asian poverty line because the heterogeneity within Asia in these economic and social arrangements is very large. Also, it would first be necessary to investigate the empirical importance of these claims and their relevance to particular Asian countries before drawing any firm conclusions on this. It should also logically lead to different poverty lines within Asia, depending on the particular circumstances. It would thus be particularly difficult to use this argument as a motivation for a uniform income poverty line appropriate for all of Asia.

A second argument relates to differences in levels and trends of economic performance that ought to be reflected in the setting of a poverty 
line. Average incomes in Asia are higher than in Africa (but lower than in Latin America and the Middle East) and most economies in Asia have experienced rapid growth in the past three decades. This might justify the use of an Asian poverty line that reflects the average income level and, more importantly, reflects its rapid economic performance. We argue below that such a poverty line should contain a relative element, that is, should increase with rising prosperity in Asia. The high heterogeneity in Asia's income levels and economic growth experience might be seen as a counterargument to a single and uniquely Asian income poverty line, but to the extent that neighboring countries benchmark their performance against each other, an argument for a unique line reflecting these special features can be made.

A third argument is that an Asian poverty line would be more closely aligned with national poverty lines in Asia and, thus, the disconnect between national and international poverty measurement would be correspondingly smaller (see Klasen 2013a; Dotter 2014). This is essentially an empirical question. Clearly, the current $\$ 1.25$ international poverty line is only very loosely linked to Asian realities. The only Asian country included in the sample of the 15 poorest countries that were used to derive the $\$ 1.25$ the poverty line is Tajikistan (Ravallion et al. 2009). In fact, it can be argued that the $\$ 1.25$ poverty line is much more a reflection of national poverty realities in Africa than in Asia (which includes only South, East, and Southeast Asia; Central Asia is included with Europe here). This can also be seen in Figure 1.1. This figure shows the difference in the poverty headcount using the national poverty line minus the headcount using the international poverty line. A negative number means that the international poverty line is higher than the national poverty line. This is the case in a number of Asian countries, including large ones (the size of the bubble indicates the number of poor people there). For these countries, the international poverty line appears high. In Europe and Central Asia, the international poverty line is far too low. An extreme case is Tajikistan where the poverty headcount using the national poverty line is 40 percentage points higher than when using the international poverty line (even though this country is included in the sample used to calculate the international poverty line). Thus, the mismatch between Asian national poverty lines and the international poverty line appears substantial, which would argue for an Asia-specific poverty line. If an 'Asian' poverty line was directly grounded in country-specific poverty lines (in contrast to the international poverty line that is an average of poverty lines across the world), the linkage between national and pan- Asian poverty measurement could be even closer. This is an issue we discuss below. 


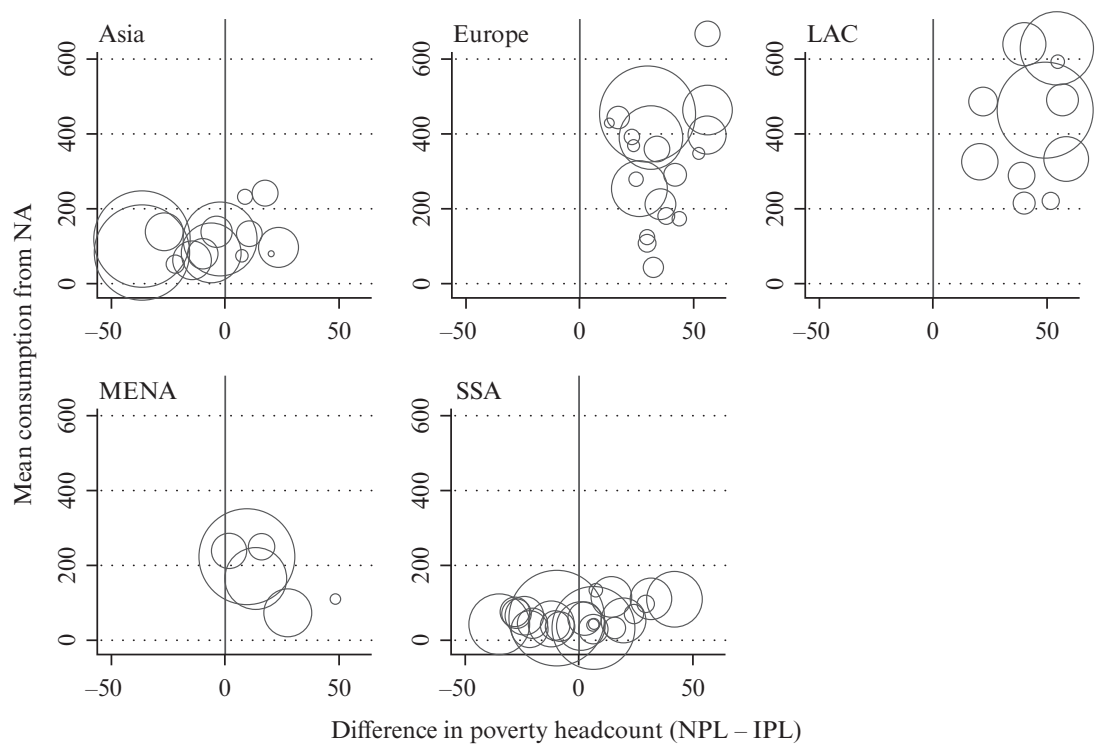

Notes: NPL refers to national poverty lines; IPL to the international poverty line ( $\$ 1.25 \mathrm{a}$ day); the y-axis measures mean consumption per capita per month, taken from the national accounts (NA). Europe includes Eastern European and Central Asian countries; LAC refers to Latin American and Caribbean countries; and MENA refers to countries in the Middle East and North Africa; where these regions refer to World Bank regional classifications.

Source: Dotter (2014).

\section{Figure 1.1 Mismatch in poverty headcount by region using national and international poverty lines}

A fourth argument relates to a multidimensional poverty measure. The most prominent internationally comparable multidimensional poverty measure, UNDP's MPI (see UNDP 2010, ch. 5; Alkire and Santos 2014), uses the same indicators and cutoffs across the entire developing world. Owing to differences in climate, economic and social arrangements, social preferences, and the nature and state of public services, it might be argued that an Asian MPI should reflect this in terms of indicators and cutoffs. For example, it could be argued that the role of education as key to personal advancement is seen as particularly important in Asian societies, and an MPI should reflect this by giving education more weight and possibly argue for a higher cutoff. As before, the heterogeneity within Asia is a problem for this line of reasoning. When considering multidimensional poverty measures below, we revisit this issue again. 
There are also disadvantages to generating a continent-specific poverty line. The most important is that comparisons across continents are difficult and lack transparency both in terms of levels and trends.

To conclude this section, it is not obvious that a specific Asian poverty line is desirable. The most compelling arguments are that it could reflect income levels and faster economic progress better than could a global measure; that it can be linked more closely to national poverty lines in Asia; and that it might reflect uniquely Asian conditions and settings in a multidimensional measure. However, there are costs to it and this suggests that a global measure should not be dropped for an Asian measure, but only treat an Asian poverty line as complementary to a global assessment.

\section{OPTIONS TO CONSTRUCT AN ASIAN POVERTY LINE}

There are different options to generate an Asia-specific poverty line. First, it is necessary to distinguish between an income and a multidimensional poverty line. When constructing an income poverty line, we consider three options. The first is to mimic the estimation method of the World Bank of generating the \$1.25-a-day poverty line, but only using Asian countries in the estimation; the second option uses the same set of countries to produce a 'weakly relative' poverty line (Ravallion and Chen 2011; Chen and Ravallion 2013); and the third option grounds an Asian poverty line in national poverty measurement (see Klasen 2013a, 2013b). Thus, together with an Asia-specific multidimensional poverty line, altogether four options are considered.

\subsection{An Absolute Income Poverty Line Using the World Bank's Methods}

The World Bank has been generating an international poverty line since 1990 (World Bank 1990; Ravallion et al. 1991). In 1990, it stood at $\$ 1.02$ in 1985 PPP-adjusted dollars; in 2000, it was adjusted to \$1.08 in 1993 PPPadjusted dollars (World Bank 2000; Chen and Ravallion 2001); and, in 2008 , it was adjusted to $\$ 1.25$ in 2005 PPP-adjusted dollars (Ravallion et al. 2009). Now, the World Bank is working on adjusting its estimated poverty line using 2011 PPP-adjusted dollars.

The methods of deriving the international poverty line have essentially been the same (although differing in some details of data used) and we focus on the latest completed revision done in 2008. Ravallion et al. (2009) explain how the World Bank derives the international income poverty line using the following steps. First, available national poverty lines for 
74 developing countries are translated into poverty lines expressed in PPP-adjusted international dollars in 2005 prices. Then, these national poverty lines (expressed in 2005 international dollars) are lined up against the log of consumption per capita (in 2005 international dollars) of the 74 countries (see Figure 1.2(a)). They then observe that, below a certain

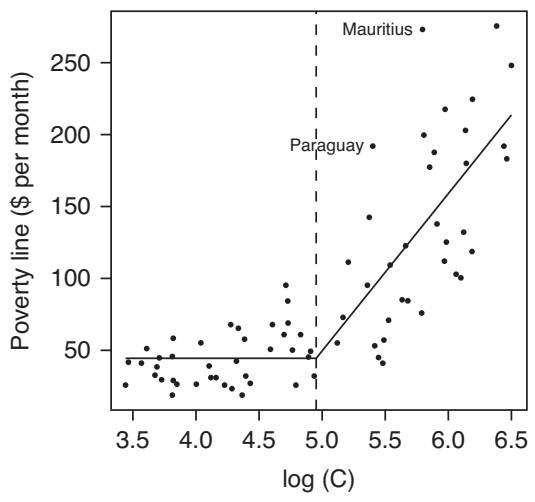

(a) Threshold model for log(consumption)

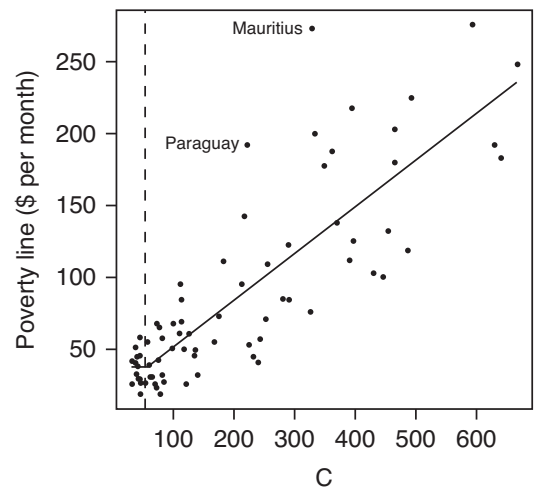

(b) Threshold model for consumption

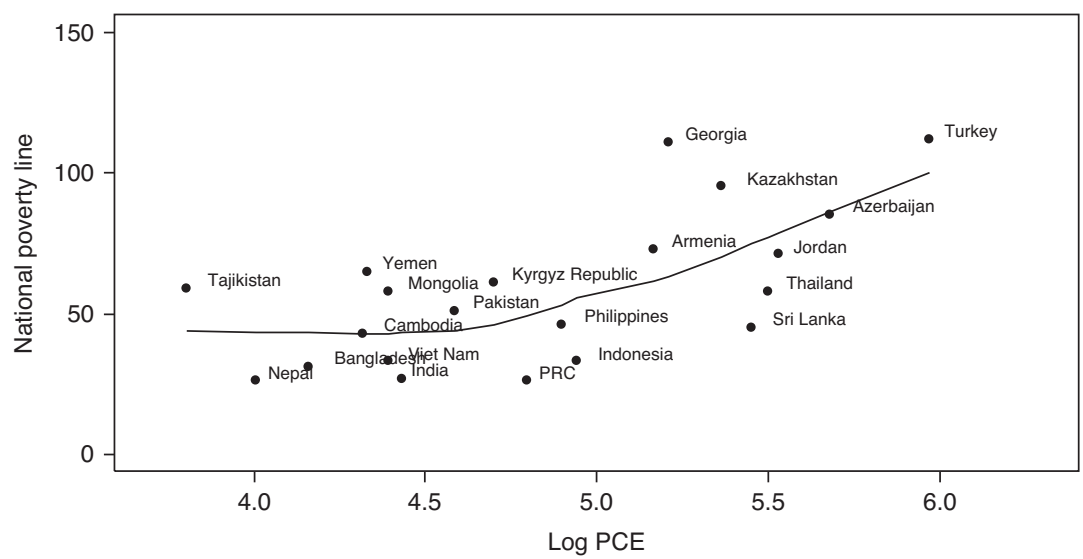

(c) National poverty lines for 21 Asian countries plotted against mean consumption in international 2005 PPP

Note: PCE refers to per capita expenditures; all figures refer to dollars per capita per month. PRC = the People's Republic of China.

Sources: (a) and (b): analysis based on Klasen et al. (2015), data from Ravallion et al. (2009); (c) elaboration of ADB (2014: 8), based on data from Ravallion et al. (2009).

Figure 1.2 National poverty lines for 74 developing countries plotted against mean consumption in international 2005 PPP 
threshold, the relationship of per capita consumption, national poverty lines are very similar, indicated by the flat portion of the curve below, whereas above a threshold they rise, less than proportionately, with mean incomes. The $\$ 1.25$-a-day poverty line is then simply the average poverty line of the flat portion.

For an Asian poverty line, simply limit the sample to 21 national poverty lines from Asian countries, as done by ADB (2014) in an illustrative exercise reproduced in Figure 1.2(c). As can be seen, also here the relationship between log per capita consumption and the national poverty lines is also nonlinear, with a flat portion below a certain threshold level of per capita incomes and an increasing portion above that. The average poverty line of the flat portion in Asia extends substantially further to the right. Whereas, in the global sample, only two Asian economies are in included in the flat portion which constitutes the reference line for the poverty line, in the Asian sample, nine countries are included in the reference group. This also leads to a substantially higher 'Asian' poverty line of around \$1.51. However, this difference between the international and the Asian poverty line is actually due to differences in the estimation method between Ravallion et al. (2009) and the estimate produced by ADB (2014). Whereas the former estimate the relationship between the level of the national poverty line and per capita consumption from the national accounts (that is, a linear model, in effect modeling the relationship in Figure 1.2(b)), ADB (2014) estimates the relationship between national poverty lines and the log of per capita consumption (that is, a log-linear model). As shown by Greb et al. (2011), using a log-linear model also leads to a larger reference group in the global model and a global poverty line of $\$ 1.45$ per day. Thus, using a sample of Asian countries does not lead to a different poverty line from using the global sample if the same estimation method is used. Nevertheless, the question arises which estimation method is to be preferred.

However, both the estimations by Ravallion et al. (2009) and by ADB (2014) are problematic from a statistical point of view. In particular, in the linear model used by Ravallion et al. (2009), there is no statistical evidence of a kink in the curve so that the kink is imposed on the data rather than observed (which is visible from Figure 1.2(b), see Greb et al. 2011; Klasen et al. 2015). In the log-linear model, the residuals are not normally distributed so that the inference, especially regarding location and significance of the kink which separates the flat from the rising portion, is problematic. As shown by Klasen et al. (2015), the preferred statistical specification is actually a log-log model where there is statistical evidence for a kink as well as normally distributed residuals. Using the latter model, a global poverty line of about $\$ 1.21$ is obtained, with a slightly larger reference group (of 19 countries). Applying this to the estimation of the Asian poverty line, we 
could then take the average of the Asian countries included in the reference group for the global line. That would result in a poverty line of about $\$ 1.28$ but only three Asian countries are included in the reference group (Tajikistan, Nepal, and Bangladesh) which makes this approach unreliable. If we instead estimated the linear or the log-log model using the 21 Asian observations, this would yield an 'Asian' poverty line of $\$ 1.41-\$ 1.43 ;^{2}$ this is driven largely by the relative high national poverty lines in Tajikistan, Yemen, and Mongolia. Also here, reliability is an issue because a nonlinear threshold model is estimated on just 21 observations where outliers and small data problems could have a large impact; it is also likely that the switch to the 2011 PPP round would lead to a substantial change in this estimate. Overall, we suggest that this method would not generate a very reliable and robust estimate for an Asia-specific income poverty line.

Besides these estimation issues, there are more serious concerns and criticisms of this entire approach, which have been discussed extensively in the literature (for example, Reddy and Pogge 2009; Deaton 2010; Klasen 2013a, 2013b; Dotter 2014; Klasen et al. 2015). We highlight four of the most important issues that have been discussed in the literature. First, this method is unstable and highly dependent on the sample of countries included in the estimation and the PPP exchange rates used. When, in 2008, the World Bank switched from using the 1993 PPPs and the sample of countries used for estimating the poverty line, it led to the switch of the international poverty line from $\$ 1.08$ in 1993 dollars to $\$ 1.25$ in 2005 dollars. Currently, similar issues are arising with the new 2011 PPPs which could lead to serious reassessments of poverty levels in the world and in different regions (Klasen et al. 2015). More seriously, the 2008 revision led to a massive upward shift in global poverty for all years, for example from about 29 percent in 1990 to about 41 percent in the same year; thus, the base year of the first MDG was changed substantially with a large impact on what halving global poverty would mean. The pace of poverty reduction was, however, less affected (Chen and Ravallion 2010). As shown by Deaton (2010) and Greb et al. (2011), the main reason for the massive increase in levels of observed global poverty was not the switch of the PPPs, but the switch in the sample of countries used to estimate global poverty. Deaton (2010) additionally noted that the change in the sample led to some perverse effects. In particular, he noted the case of India. Whereas India was part of the reference group of countries that made up the global poverty line using 1993 dollars, high subsequent growth ensured that India was no longer in the reference group in the assessment using 2005 dollars. Because India's poverty line is rather low, the exclusion of India from the reference group led to an increase in the global poverty line, which, in turn, led to an increase in measured poverty in India using 
that new line. In a sense, rapidly rising incomes in India have led to higher observed poverty in India using the international poverty line, clearly a problematic effect. In short, there appear to be substantial problems and uncertainties associated with switches in PPPs and national poverty lines used to estimate the global poverty line. The 2011 PPPs suggest that prior assessments of PPP-adjusted incomes underestimated per capita incomes in the PRC and India, and some other Asian economies. If these are used to generate a new international poverty line, this could have substantial implications for poverty in those countries, compared with other regions, as well as on global poverty.

A second line of criticism relates to the use of PPPs more generally for this type of assessment (Reddy and Pogge 2009; Deaton 2010; Klasen 2013b). One criticism is that PPPs are generated to compare overall price levels, not price levels for the poor; worse, they can be sensitive to changes in the price level for goods unrelated to the poor (Reddy and Pogge 2009). Another criticism is that PPPs are only valid for a particular benchmark year, but not over time. Thus, the question arises whether one should use only one PPP benchmark year (as currently being done in the World Bank's approach to poverty measurement), or several benchmark years (as done for the Penn World Tables that also use PPP-adjusted income data).

A third line of criticism is that the international income poverty line has limited relevance for country-level poverty assessments because the difference between country-level income poverty lines and the international income poverty line is substantial (Dotter 2014). This point, already alluded to above, is nicely visible in the estimation of the Asian poverty line in Figure 1.2(c). As can be seen, the difference between countrylevel poverty lines and the estimated Asian poverty line is substantial. In Tajikistan and Yemen, poverty using the Asian poverty line is much lower than when using national poverty estimates, whereas in Nepal and India it is much higher. In fact, there is a clear regional pattern to the difference between national poverty lines and an Asian poverty line. All South Asian countries are below the estimated line, that is, poverty is lower using national poverty lines than the international poverty line. The converse is the case for all Western and Central Asian countries that were part of the former Soviet Union. There, national poverty lines are all above the line; thus, poverty is much lower using the common Asian poverty line. This clear regional pattern appears problematic and suggests substantial problems with one common Asian poverty line.

A fourth criticism of such an approach, closely related to the one just discussed, is the increasing irrelevance of the $\$ 1.25$ poverty line for an increasing number of Asian countries. In many Asian economies, this poverty line is simply too low to be relevant for policy makers there. In 
fact, several Asian countries, including the PRC and India, have recently increased their national poverty line to make it more relevant for national policy making. In this context, the question arises whether one should adjust the poverty line because of increasing prosperity. This is precisely the suggestion by Ravallion and Chen (2011) of a 'weakly relative' international poverty line to which we turn below.

To summarize, the case for an Asian poverty line using the World Bank's method of deriving the $\$ 1.25$ poverty line is weak. It would not lead to a substantially different poverty line, it is poorly linked to national poverty lines, it is unstable due to the link to the PPPs and the estimation method, and it would be increasingly irrelevant for fast-growing Asian economies.

\subsection{A 'Weakly Relative' Poverty Line Using the World Bank's Approach}

Ravallion and Chen (2011) proposed a 'weakly relative' international poverty line. It can be derived in various ways, but the easiest is to consider Figure 1.2(a) again. The suggestion is that for countries on the flat portion of the curve, the $\$ 1.25$-a-day should be the relevant line. For those on the ascending portion of the curve, the poverty line should rise with the increase in mean income. It turns out that the best empirical fit is that, above the threshold, the poverty line should increase by $\$ 0.33$ for every $\$ 1$ increase in per capita consumption of a country above the threshold (Ravallion and Chen 2011; Chen and Ravallion 2013). The elasticity of the weakly relative poverty line is substantially below 1 (but increases with increasing incomes), which distinguishes it from a purely relative line.

Such a weakly relative poverty line has several features that make it advantageous to be used for an Asian poverty line (see Klasen 2013a; Klasen et al. 2015). First, it adjusts the poverty line 'automatically' with increasing prosperity in Asia, thereby addressing the problem of the increasing irrelevance of the very low $\$ 1.25$-a-day poverty line. As shown by Chen and Ravallion (2013), the weakly relative poverty line in East Asia, for example, is about $\$ 2.34$ in 2008, and, in South Asia, it is \$1.94 (see Appendix Tables A1.1 and A1.2). Given that this poverty line increases under-proportionately with mean income, distribution-neutral growth will still lower 'weakly relative' poverty, but will do so at a slower pace than when using a purely absolute line. As can be seen in Appendix Tables A1.1 and A1.2, there was still substantial poverty reduction in Asia using this approach, but poverty remains a very serious issue.

Thus, the 'weakly relative' poverty line has some advantages. At the same time, all the other disadvantages of the World Bank's method remain, 
so it is not clear whether this is the best way forward. However, it clearly seems to be superior to simply deriving an Asian absolute poverty line using the World Bank's method.

\subsection{Using National Poverty Lines to Measure Poverty in Asia}

A third approach of setting an income poverty line is to coordinate a process in Asia of setting national poverty lines using a standardized methodology. These national poverty lines would be expressed in national currency but could still aggregate the poor across countries in a consistent fashion if the poverty lines were consistently derived. This proposal was made by Reddy et al. (2008) and later by Klasen (2013a, 2013b) and Klasen et al. (2015). One advantage is that the problems associated with the PPP exchange rates would be avoided. A second advantage is that such a poverty line would be more closely linked to national poverty measurement and, thus, would have a higher relevance.

At the same time, a range of questions would need to be addressed before such a proposal could be implemented (see Klasen 2013b for an extensive discussion). First, how should such a poverty line be grounded? The most promising approach would be to use the method most commonly used to set national poverty lines in developing countries, that is, the cost of basic needs method (Ravallion 1994). This method involves first identifying a reference group of households (which should be close to the poverty line) whose spending pattern would be used to derive expenditure shares on a basket of goods and services used to assess poverty. In a second step, the food expenditures in that basket are turned into calories and then the basket is scaled up (or down) to reach the required caloric norm for households. This basket (including non-food items) then defines the quantities of food and non-food items to be consumed at the poverty line. The cost of that basket then yields the poverty line. This poverty line is then updated for price changes of goods included in the basket over the years. However, over longer time periods the basket is adjusted to reflect changing expenditure patterns. In a rapidly growing economy, this usually means that the basket changes by reducing the food share and increasing more higher-quality goods. In this way, relative poverty considerations can be brought in when the poverty basket is adjusted.

Although the methods are straightforward and have been applied in many countries (including in Asia), setting these poverty lines in a consistent fashion across countries is challenging. The first-best option would be for participating countries to agree on a consistent system of poverty measurement using this approach. It would ideally also include coordinating household surveys so that the questionnaires are similar enough that 
they can be used consistently. The model would be the System of National Accounts where a similarly coordinated process of standard methods is accepted across the world.

At the same time, it is unlikely that such a coordinated way to set national poverty lines would be agreed upon quickly. In the meantime, a second-best option would be to use existing household surveys from these Asian countries and apply consistent poverty lines in these surveys, even if these lines are not the current approaches used by the governments. In this way, the feasibility of this approach could be demonstrated, thereby moving the debate forward.

Therefore, this approach is promising but requires a longer-term process to implement it fully. However, as suggested, a short-cut is possible and it is useful to illustrate the feasibility of this approach.

\subsection{An Asia-specific MPI?}

Finally, there is the Asia-specific MPI option to consider. It is widely recognized that poverty is a multidimensional phenomenon. The challenge has always been to come up with a set of indicators and weights that would allow for a consistent analysis of poverty over time and across space. With the publication of the MPI in 2010 (UNDP 2010, ch. 5), a first attempt to create such a comparable poverty measure was made. It uses a so-called dual cutoff method proposed by Alkire and Foster (2011) where the first cutoff defines whether a household is deprived in a particular dimension, and a second cutoff defines whether a household has passed the threshold of deprivations to be called multidimensionally poor.

Although there are many questions of details that still need to be addressed (Dotter and Klasen 2014), it now appears feasible to generate an Asia-specific version of such an MPI. As discussed above, it would first be necessary to think through why and how an Asian MPI would have different indicators, cutoffs, or weights. This is not a straightforward question and has to deal with the great heterogeneity among Asian countries. Although it may be argued that, because of differences in climate, social structures, or values in particular sub-regions (for example, South Asia, Southeast Asia and Central Asia), appropriate indicators, cutoffs, and weights could be chosen to generate MPIs for these different sub-regions, it would be hard to develop an MPI for all of Asia. The only way out of this dilemma would be to initiate a process, possibly at the level of the ADB, to develop a common understanding for indicators, weights, and cutoffs, although it is expected that such a consensus would not be reached easily.

A second way by which one could construct an Asian MPI that differed less fundamentally would be to adjust cutoffs to better reflect the average 
performance of Asian economies in these MPI indicators. For example, a cutoff of five years of education of a single household member to render the entire household non-poor, as currently used in the MPI, might be too low for many Asian countries. Thus, the idea would be to move away from an absolute indicator of acute multidimensional poverty to a (weakly?) relative one that considers the performance of Asian economies in these indicators.

A third approach would be to change the weights used for an Asianbased multidimensional poverty line. Here the results from the illustrative exercise of Pasha (2014) are interesting. She uses principal components analysis to derive statistical weights for the indicators included in the MPI. Pasha (2014) finds substantial differences across countries in these weights. In India, the weights for child mortality and nutrition are higher than in all the 22 countries included in her sample. Conversely, the weights for education are low. The weights for standard of living are very high (altogether 80 percent), with quality of floor and access to cooking fuel particularly important. Using such country-specific weights would lead to quite different multidimensional poverty measures and might provide interesting new insights. It would also lower the ability to compare levels and trends across countries. Clearly this is an issue well worth exploring further.

\section{SOME TENTATIVE CONCLUSIONS}

This discussion suggests that the case for developing an Asian poverty line is not straightforward. In particular, we have argued that there are no good reasons to adjust the World Bank's \$1-a-day approach to an Asian setting. Many of the problems of the World Bank's international poverty line would carry over to its Asian version; in addition, the database to estimate such a poverty line would be even smaller, leading to questions of reliability and robustness. Also, the large heterogeneity in existing poverty lines in Asia would militate against this proposal. A more promising option is to consider a 'weakly relative' Asian income or non-income poverty line that takes into account the rapid growth in living conditions and aspirations in many of Asia's economies. However, many of the drawbacks of the current international poverty line would carry over to the 'weakly relative' case. Even more promising could be a coordinated process for setting national income poverty lines where national poverty measurement is based on a common conception of poverty. This is a long-term agenda that would need a great deal of coordination between Asian economies but is well worth pursuing further. Another option would be the creation of an Asia-specific MPI, maybe one that adjusts itself automatically to improving living conditions by adjusting the cutoffs. All of these proposals 
would have to be rigorously tested to see whether they can be implemented and yield new insights that are not visible in current approaches to poverty measurement in Asia.

The discussions about the changes in the international poverty line to reflect the results of the 2011 PPP show the difficulty of maintaining a reliable, consistent, and robust international poverty line (Klasen et al. 2015). Thus, it is all the more important to consider alternatives.

\section{NOTES}

1. I would like to thank Xuehin Han, Guanghua Wan, Jacques Silber, Tatyana Krivobokova, and George Battese for helpful inputs, comments, and discussion on earlier versions of the chapter.

2. I thank Tatyana Krivobokova for providing these estimates, based on the methods described in Klasen et al. (2015).

\section{REFERENCES}

Alkire, S. and J. Foster (2011a), 'Counting and multidimensional poverty measurement', Journal of Public Economies, 95 (7), 476-87.

Alkire, S. and M.E. Santos (2014), 'Measuring acute poverty in the developing world: robustness and scope of the Multidimensional Poverty Index', World Development, 59, 251-74.

Asian Development Bank (ADB) (2014), Poverty in Asia: A Deeper Look, Manila: Asia Development Bank.

Chen, S. and M. Ravallion (2001), 'How did the world's poor fare in the 1990s?', Review of Income and Wealth, 47 (3), 283-300.

Chen, S. and M. Ravallion (2010), 'The developing world is poorer than we thought, but no less successful in the fight against poverty', Quarterly Journal of Economics, 125 (4), 1577-625.

Chen, S. and M. Ravallion (2013), 'More relatively poor in a less absolutely-poor world', Review of Income and Wealth, 59 (1), 1-28.

Deaton, A. (2010), 'Price indexes, inequality, and the measurement of world poverty, American Economic Review, 100 (1), 5-34.

Dotter, C. (2014), 'The (ir-)relevance of the international poverty line for national poverty assessment', mimeograph, University of Göttingen.

Dotter, C. and S. Klasen (2014), 'The Multidimensional Poverty Index: achievements, conceptual and empirical issues', UNDP HDRO Occasional Paper, UNDP, New York.

Greb, F., S. Klasen, S. Pasaribu and M. Wiesenfarth (2011), 'Dollar a day rerevisited', Courant Research Center Discussion Paper No. 91, University of Göttingen.

Klasen, S. (2013a), 'Is it time for a new international poverty measure?', in E. Solheim (ed.), Development Cooperation Report 2013: Ending Poverty, Paris: OECD. 
Klasen, S. (2013b), 'Measuring levels and trends in absolute poverty in the world: open questions and possible alternatives', in G. Betti and A. Lemmi (eds), Poverty and Social Exclusion: New Methods of Analysis, London: Taylor and Francis.

Klasen, S., T. Krivobokova, F. Greb, R. Lahot, S. Pasaribu and M, Wiesenfarth (2015), 'International poverty measurement: which way now?', Courant Research Center: Poverty, Equity, and Growth Discussion Paper No. 184, University of Göttingen.

Klasen, S. and H. Waibel (2013), Vulnerability to Poverty, London: Palgrave.

Klasen, S. and H. Waibel (2014), Vulnerability to poverty in South-East Asia: drivers, measurement, responses, and policy issues, World Development, DOI: http://dx.doi.org/10.1016/j.worlddev.2014.01.007.

Pasha, A. (2014), 'Regional perspectives to the Multidimensional Poverty Index', mimeograph, University of Göttingen.

Ravallion, M. (1994), Poverty Comparisons, Fundamentals of Pure and Applied Economics, vol. 56, Chur: Harwood Academic.

Ravallion, M. and S. Chen (2011), 'Weakly relative poverty', Review of Economics and Statistics, 93 (4), 1251-61.

Ravallion, M., S. Chen and P. Sangraula (2009), 'Dollar a day revisited', World Bank Economic Review, 23 (2), 163-84.

Ravallion, M., G. Datt and D. van de Walle (1991), 'Quantifying absolute poverty in the developing world', Review of Income and Wealth, 37 (4), 345-61.

Reddy, S. and T. Pogge (2009), 'How not to count the poor', in S. Anand, P. Segal and J. Stiglitz (eds), Debates on the Measurement of Global Poverty, Oxford: Oxford University Press.

Reddy, S., S. Visaria and M. Attali (2008), 'Inter-country comparisons of income poverty based on a capability approach', in K. Basu and R. Kanbur (eds), Arguments for a Better World, vol. 2, Oxford: Oxford University Press.

Rippin, N. (2013), 'Considerations of efficiency and distributive justice in multidimensional poverty measurement', $\mathrm{PhD}$ dissertation, University of Göttingen.

United Nations Development Programme (UNDP) (2010), Human Development Report, New York: UNDP.

World Bank (1990), World Development Report 1990: Poverty, New York: Oxford University Press.

World Bank (2000), World Development Report 2000/01: Attacking Poverty, Washington DC: World Bank. 


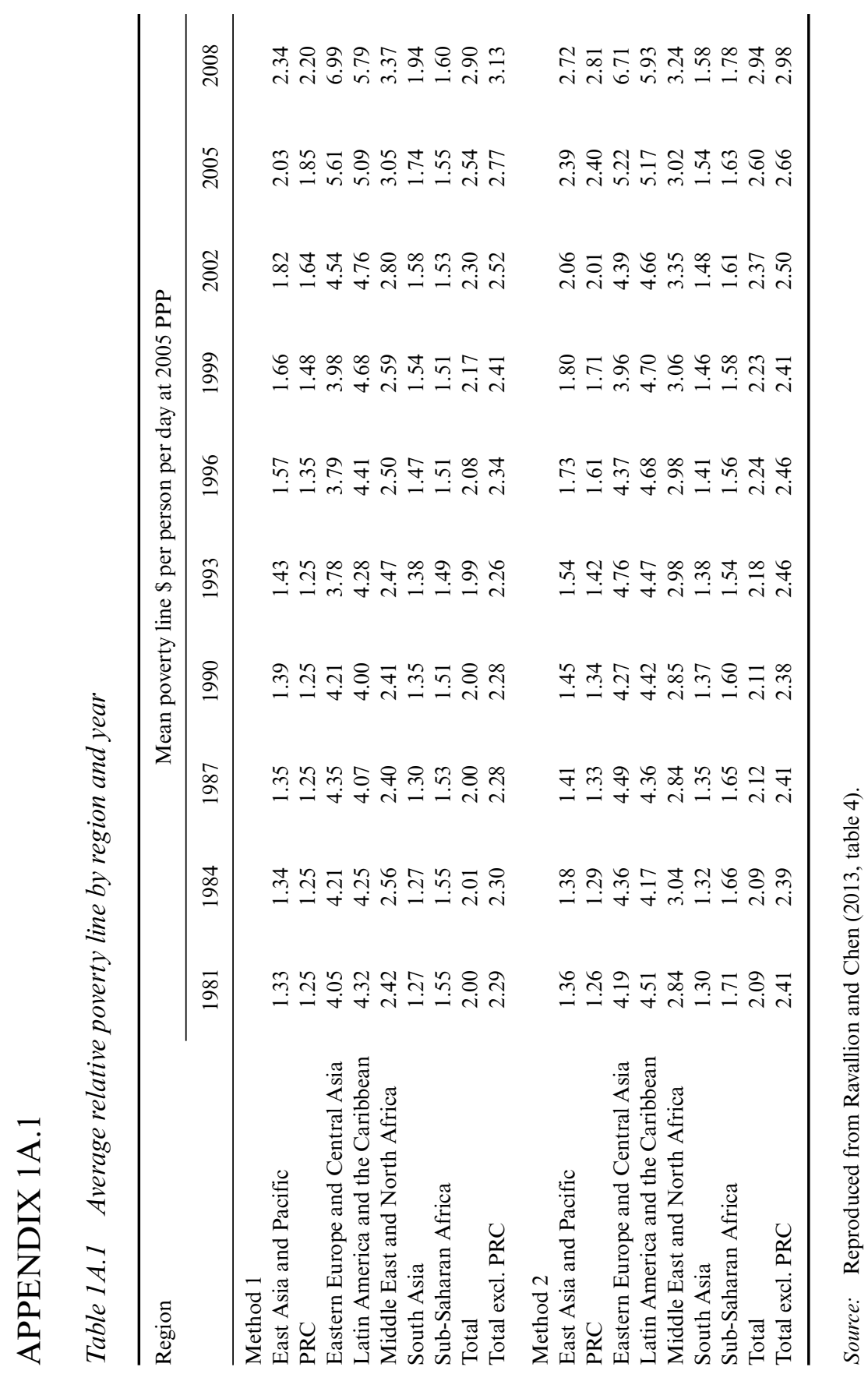




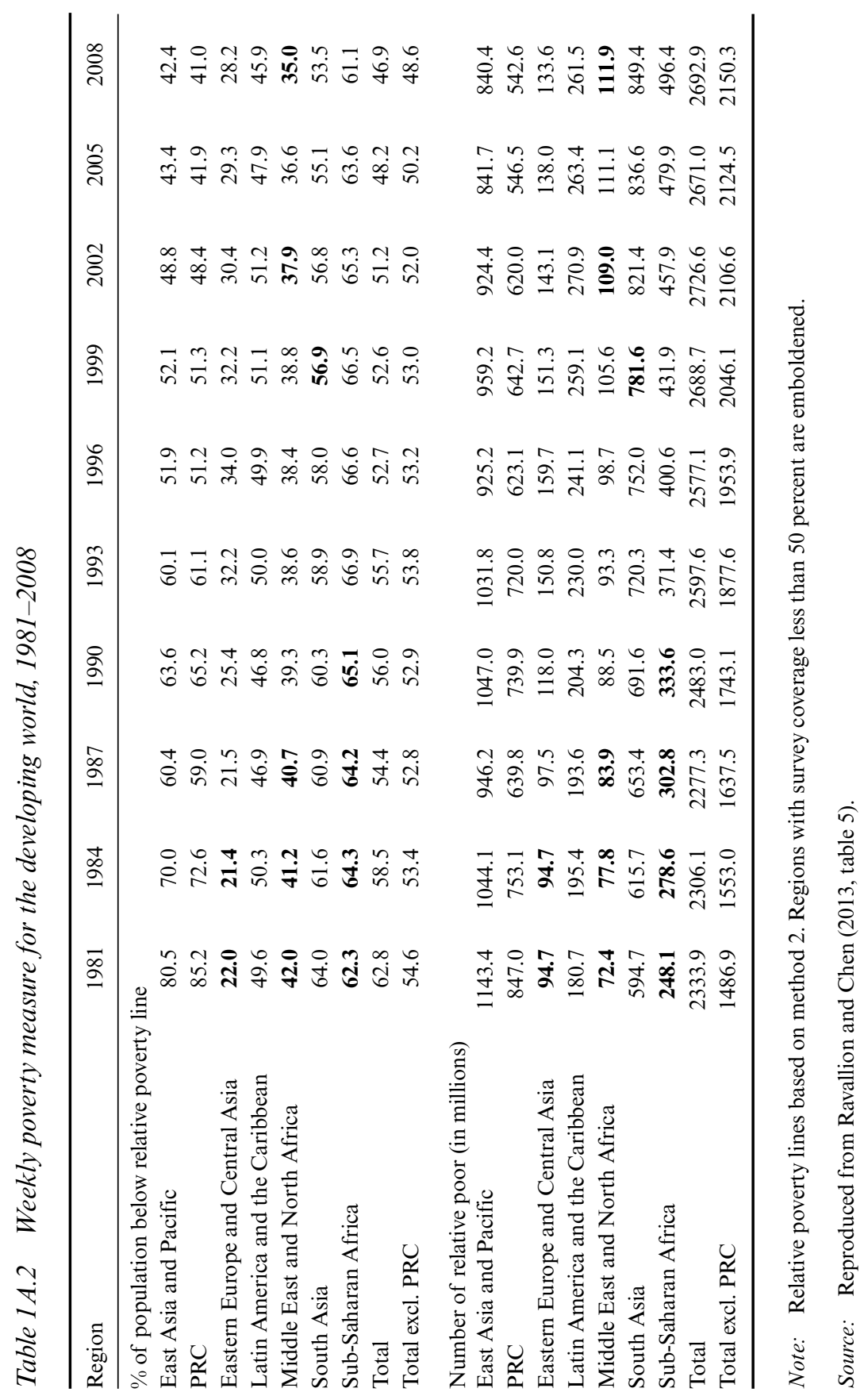

